\title{
D.Y. Béchard, Vandal love ou perdus en Amérique
}

\section{Simona Rossi}

\section{(Q) OpenEdition}

\section{Journals}

\section{Edizione digitale}

URL: http://journals.openedition.org/studifrancesi/8129

DOI: 10.4000/studifrancesi.8129

ISSN: 2427-5856

\section{Editore}

Rosenberg \& Sellier

\section{Edizione cartacea}

Data di pubblicazione: 1 juillet 2009

Paginazione: 458-459

ISSN: 0039-2944

\section{Notizia bibliografica digitale}

Simona Rossi, «D.Y. Béchard, Vandal love ou perdus en Amérique», Studi Francesi [Online], 158 (LIII | II) |

2009, online dal, consultato il 13 janvier 2021. URL: http://journals.openedition.org/studifrancesi/ 8129 ; DOI: https://doi.org/10.4000/studifrancesi.8129

Questo documento è stato generato automaticamente il 13 janvier 2021.

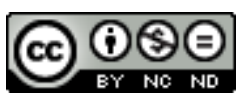

Studi Francesi è distribuita con Licenza Creative Commons Attribuzione - Non commerciale - Non opere derivate 4.0 Internazionale. 


\title{
D.Y. Béchard, Vandal love ou perdus en Amérique
}

\author{
Simona Rossi
}

\section{NOTIZIA}

D. Y. BÉCHARD, Vandal love ou perdus en Amérique, Montréal, Québec Amérique, 2008, pp. 342.

1 Un titolo davvero enigmatico per il primo, affascinante romanzo di Béchard, il cui nome è indicato soltanto da due lettere puntate. Chi sono coloro che si sono persi in America, coloro che errano alla ricerca di loro stessi e di un percorso di vita che abbia un senso? Si tratta di nani e giganti. Sì, i protagonisti messi in scena da questo fantasioso e sensibile scrittore gaspesiano sono proprio dei nani e dei giganti. Racconto multigenerazionale che si snoda dall'inizio del Novecento fino ai giorni nostri, Vandal love dà vita alla saga di una famiglia caratterizzata da una particolarità davvero fuori dal comune: procreare alternativamente nani e giganti. Ognuno con le problematiche tipiche della propria condizione fisica, questi esseri si muovono nel grandioso contesto nord-americano, la cui natura, fatta di minuscoli, poetici dettagli e grandiosi scenari, sembra adattarsi perfettamente ai movimenti e alle fattezze dei personaggi.

2 La trama, densa di intrecci, di figure secondarie e di cambiamenti repentini, si sviluppa in due libri distinti: il primo, riguardante la discendenza dei giganti della famiglia Hervé, vede il "piccolo" Jude rimanere solo col nonno, Hervé Hervé, a causa dell'abbandono della madre e della nonna. Una volta adolescente, Jude deciderà di lasciare la Gaspésie e di prendere la via degli Stati Uniti, dove lo attenderanno una breve carriera da boxeur e un legame infelice con una meticcia, Louise, che gli darà una figlia. La sua vita sarà continuamente punteggiata da esili ed abbandoni, partenze ed arrivi, in una girandola estenuante e priva di epilogo. Jude dovrà spesso anche fare $\mathrm{i}$ conti con la propria forza bruta e con il senso di colpa che lo perseguita ogni giorno, perché, suo malgrado «un géant finit toujours pour avoir l'air coupable» (p.43). Il secondo libro, invece, si apre con la vergogna di Hervé Hervé per i suoi figli nani, che 
vende ad altre famiglie. Questo provoca la partenza della moglie Georgianne, che in seguito ad una visione, parte alla ricerca del figlio Jean. Non lo troverà, ma percorrerà un cammino di dolorosa separazione e di ricerca di sé, adottando, alla fine, un bambino nano che crescerà come suo. È un libro da comprendere, Vandal love, da sondare in ogni sua più piccola sfaccettatura, un libro su cui riflettere con calma e tenacia. Inizialmente il lettore che si avventura nelle sue pagine può forse rimanere interdetto, ma a poco a poco l'originalità del soggetto cattura con garbo, il linguaggio, ardito e complesso, crea talvolta stupore come l'inedita mescolanza tra realismo storico, immagini fantastiche e pungenti allegorie, il sarcasmo malinconico lascia intravedere spicchi di filosofia.

3 Sono molti i temi del romanzo di Béchard su cui riflettere: il limite tra normalità e anormalità; il bisogno dell'uomo di fare i conti con se stesso e di trovare un luogo a propria misura in cui stabilirsi; la peregrinazione interiore che conduce a quella reale. $\mathrm{Ma}$ al di là della riflessione critica e dell'apprezzamento per la trama, ciò che è sicuramente degno di nota in questo romanzo è soprattutto lo stile, sfrontato e disponibile a tutti gli apporti. Uno stile nuovo, che fa di Vandal love un libro solitario ma eccellente, privo di echi e somiglianze con altri filoni letterari. 